\title{
Using Puppets Making To Promote Engagement and Motivating In Educational Study
}

\author{
${ }^{1}$ Simanta Sarma, ${ }^{2}$ Binita Devi,

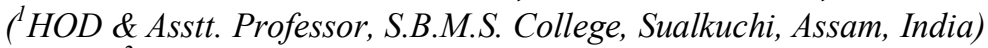 \\ ('Principal, Surojit Academy, Guwahati, Assam, India)
}

\begin{abstract}
The PUPPETS uses puppets as a stimulus for children to engage in conversations involving reasoning in education. Data were gathered using technically a variety of methods, including audio and video recording, and analysed using an open coding approach based on grounded theory. The data indicate that puppets are engaging and motivating for children; that they promote talk involving reasoning; that they can be particularly effective with reluctant speakers; that they appear to be effective across the whole primary age range; and that they promote significant changes in teachers' professional practice. We discuss different types of puppet dance \& making process. This process style developed of new generation. We examined scientifically \& technically modernized in puppet dance.
\end{abstract}

Keyword: String Puppet, Rod Puppet, Glove Puppet, Shadow Puppet, Water Puppet, Paper Puppet, Making of Puppet, Stage Show, Vandana, Sutradhar, Putla Nach.

\section{Introduction}

Puppetry is the most prominent division of theatre in India. Puppetry is close to the hearts and minds of the people, as it has a personal and intimate appeal, along with a familiar format and content, because of the colloquial dialects used. But, ironically, puppetry as a popular folk art is not given its due in the arena of performing arts in India by many schools of experts. Scholars agree on one hand that India is the birthplace of puppetry, but on the other, with reference to performing arts, they marginalize its importance by terming puppetry as "child's play".

Though puppeteers and puppet-scholars of North East India have been engaged in the revival of regional puppets, however, this art form is mostly unknown to the rest of the country. It is believed that Srimanta Sankaradeva brought puppets into Assam from Orissa, thus taking puppetry back to the early fifteenth century. The disciples of Sri Sankaradeva started practising this art form at the various Satras which were set up at Majuli- the largest river island in the world. Locally designated as Putula-Bhaona or Putula-Naach, the first performance organised at the Satras of Majuli was called Chinyajatra Naat, where a combination of both Gayan and Bayan i.e song and dance, was used and the performance was given on Bayumondal Raag, Basanta Raag etc.

Puppet is most popular Culture in world. Puppets are different types in India. There are basic four kinds of Puppet-String Puppet, Rod Puppet, Glove Puppet, Shadow Puppet.

Following were the objectives of the study.

\section{Objectives}

1) To study the folk culture and modern techniques in Puppet making. Unlike traditional methods, the movement of eyes and mouth can be shown with the help of modern techniques. Earlier, the puppets didn't have legs, their lower portion were covered with clothes but now a days, the puppets contain legs which can function like humans and it makes them more attractive.

2) To examine the cost effectiveness of making puppets. Now days, puppets can be made from thermocol, paper etc. which reduces weight of the puppet and also minimizes the expenditure.

\section{Rational of the Study}

The study may have the following social impact

(i) Promote and preserve traditional culture: The first objective of this project is to promote and preserve traditional culture through give people training of making puppet and how puppet stage show arrange.

(ii) Entertainment: Puppet is the most ancient form of entertainment. So the objectives of the project are providing entertainment to the masses through the use of modern techniques. The prime motivation of this project has always been entertainment-cum-education among the masses. The show performed in flickering lights, has been providing mirth and laughter by way of joyous entrainment. 
(iii) Provide education: Puppetry is the best form of education. In the ancient time Sankardev aim was provide moral and religious education to the people of Assam through puppet show.

(iv) To introduce children to the experience of puppet theatre: To introduce masses modern experience of puppet theatre; modernize the puppets, script, puppet show etc. Puppetry imbibes elements of all art forms such as literature, painting, sculpture, music, dance, drama and enables students to develop their creative abilities.

(v) Social awareness and message: Another objective is increase social awareness and provide message through stage program. The Project aim at production of simple puppets out of easily available and waste materials to convey educational concepts and create awareness of social issues.

(vi) Communicate: As puppetry is primarily a visual art, it can communicate to people who are not literate or who do not understand spoken language. Special sessions on drawing, movement and mime, creative writing, creative speech, dialogue delivery, voice modulation are also organised for participants to enhance their communication skills.

\subsection{String Puppet:}

\section{Different types of Puppet}

The string puppet (or marionetter) is a figure with multiple joints and suspended by a string which is controlled. String puppets are found in Rajasthan, Orissa, Assam, Tamil Nadu and Karnataka. In this, the stress is more on the manipulative skills of the puppeteer. Examples :

- Katputali shows of Rajasthan

- Sakhi Kundhei of Orissa

- Putla Nach of Assam

- Malasutri Bhaulya of Maharasthra,

- Bommalattam of Tamilnadu

- Gombeyatta of Karnataka

\subsubsection{Puppet Making:}

In traditional, the puppets are made of solapith or some soft wood by joining together different parts forming the head, torso and limbs with the help of cloth. They cover the head and hand with a paste of clay and cow dung, and colour them. Some puppets have joints in elbows but no legs. The lower portion is normally covered with cloth so that, while manipulated, the figures glide smoothly along the floor of the stage. The size of the puppets varies from 1 foot to 3 feet.

Now we make puppet through thermocol, play board, paper, hard board, cloth etc.

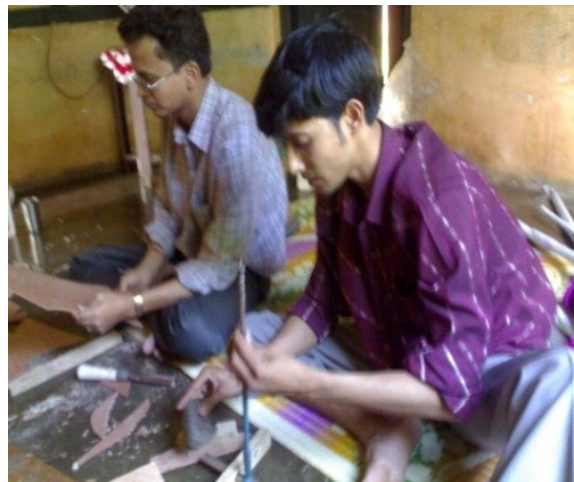

Figure1: Puppet Making

\subsubsection{Puppet Stage Making}

The stage is small and simple. A frame is put up with a few bamboo posts. Within this frame, a small platform, measuring about 10 to 12 feet in length and 3 to 4 feet in breadth, is raised on one side at a height of about 3 feet from the ground. Three sides of the frame are covered other than the platform side. Upper and lower portions are covered with screens, leaving a space of about 3 to 4 feet open along the length of the platform. At the back of the platform is another screen, normally black, standing about 4 feet, behind which the manipulators stand either on the ground or on a low bench and are not visible. A bamboo stick called Kathi achieves control.

A manipulator can easily manipulate two puppets with two hands, but an expert player can handle up to 4 to 5 puppets at a time! The speeches are made in a high-pitched, squeaking sound by a Pyapa (whistle) made of bamboo frame with a leaf or rubber membrane. The leader enters into a conversation with the characters speaking in a shrill voice in a skilful manner. 


\subsubsection{Puppet Stage Show}

A traditional show starts with the playing of special rhythmic patterns singing of Vandana (invocation) and other special songs. Then come Kalu-Bhelu or Kalua-Bhelua: two puppets who sweep the stage floor. Often a modern-looking figure, calledChengra or Mastan, not only indulges in horseplay but also passes social comments. Nowadays, even many traditional and semi-traditional troupes are given to the influence of the extremely popular mobile theatre and are starting their shows with short dance-dramas in place of the conventional preliminaries.

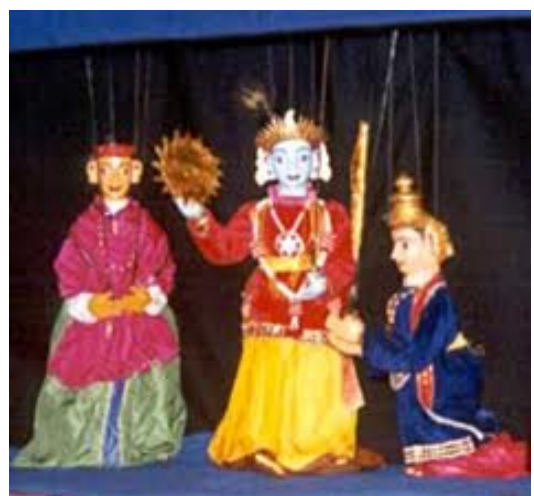

Figure 2: Puppet Stage Show

Generally, 500 to 700 people come to see a show and audiences like to see mythological plays. Rich persons or management committees of the village-fairs sponsor the shows. They go to other states to perform their plays. Sometimes they have ticket system in fairs. Women generally do not take part. Using folk tunes, they play themes like Rama Banabas, Sita Haran, Bali Badh, Sita Swamvar from Ramayana. Characters enter from the left side and exit from right. Sometimes thrones and chairs are used for the set.

One group has 80 to 90 puppets, with each puppet used for many characters. Sutradhar, joker, dancer, dholak player and kartal player are present in all plays. They keep the puppets in back-stage in a sequence. They have one puppet Tadaka(demon) whose neck can be long. They keep each puppet in the bamboo box and hang it on a pole. Occasionally, troupes take up stories from Mahabharata,Bhagavata and historical episodes like Sati Behula, Sati Jaimati, etc. Modern troupes perform all kinds of themes including old classics, romances and fantasies.

The art is hardly ever a purely family business. They are at best semi-professionals who earn a little extra cash, now and then, from their performances. It is true that normally the economic status of the puppeteers has been rather low. They are invited to perform on such occasions as village fairs and in festivals and also rarely on occasions like marriage ceremonies. The winter season, when the farmer-artists are free from their agricultural chores, is the best time for the puppet shows.

Today, while puppetry has made its way into the cities, traditional puppetry is dying a slow death. Modern puppetry on the other hand, is gaining momentum, albeit slowly, and is often used as a tool for imparting social messages. Puppeteers now tell stories on everything from medieval kings, 'Phulan-Devi, 'Aladin', 'Tejimala', 'Witch-Craft' to AIDS because to survive in this digital world, revolution has become a necessary component for this centuries old craft. To save puppetry from becoming a museum piece more needs to be done for its promotion with responsibility and clear objectives.

\subsubsection{Pupeet Process:}

String Puppet is the most popular dance in Assam. The String Puppets of Assam are known as PutulaNaach, Putula-Bhaona and Putula Bhaoriya. The string puppet of Assam is called Putala Natch and has three categories. The first is popular in lower Assam, particularly in Kamrup and Mongoldoi area. Khulia Bhoariya is a famous folk-form of lower Assam and puppeteers take stories, costumes and styles from Khulia Bhoariya, to present Putala-Bhoariya. In the same manner, Bhaona is a popular folk form of upper Assam and their puppet show imitates this form, called Putala-Bhaona. The puppets are made of solapith, without any legs and the heights vary from 1 to 3 feet. The characteristics of these puppet theatres are: Bayen (Sutradhar), who is the producer, director and coordinator of the show; two puppets Kalua and Bhelua, who sweep the stage; and a modern looking figure, called Changra, who passes social comments. The second category is seen in Mazuli, the largest river island of the world, where the disciples of Sankaradeva established a lot of Satras (hermitage). 


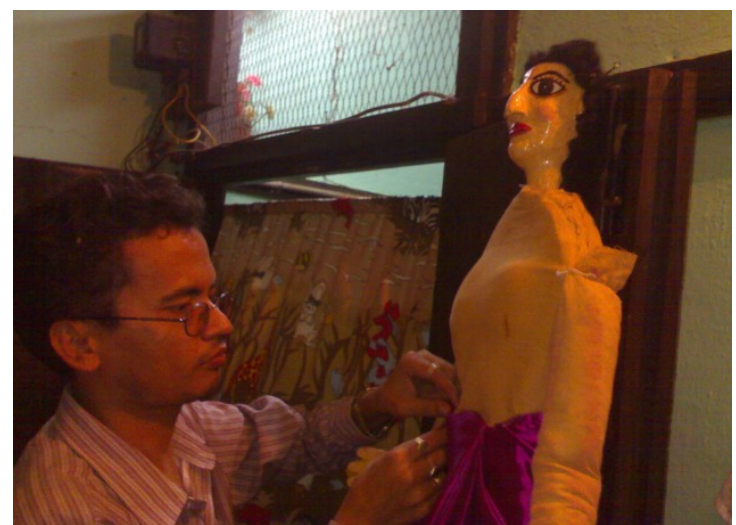

Figure 3: Puppet Costume design

Shows are performed only in Satras against dakshina (payment). The small wooden puppets have strong resemblance to Oriya style. They follow the stories and presentation style of folk-form Ankia Nat, developed by Sankaradeva. A single actor memorises all the plays, which is a unique characteristic of its kind. The third category is seen in Kalaigaon of Darang district. A group from Nadia, West Bengal, is believed to have come here and initiated the formation of local groups. A few group leaders are Bengali, using Bengali language in their shows, along with Karbi and Assamese songs and dance, and performing mainly in Bengalispeaking areas. These groups started in the seventies and remain heavily influenced by the mobile theatre of Assam.

\subsubsection{Puppet Script}

Puppetry in Assam was deeply rooted in its religious ethos. The performance of the Putula Naach showcased stories from the Ramayana and the Mahabharata. Themes like Ram-Banvas, Sita Haran, Marichar Dwara Hiran Rup Dharan etc were enacted on stage with life - like puppets. The response of the public towards the shows was also quite positive. But, with the advent of new media and the mobile theatre industry incorporating modern technology for making its performances more attractive, the popularity of the puppet shows started declining. What was earlier an indispensable component at the fairs and festivals of Raas, Paal Naam, Janmastami, started losing ground because of public apathy. And, as a consequence, this art form is at present facing total extinction at Majuli, which was its birthplace.

\subsection{Glove Puppet}

Glove puppets are mostly found in Orissa, Kerala and Tamilnadu. Puppeteers wear them on the hand and manipulate their heads and arms with their fingers. The puppeteer narrates his story in verse or prose, while the puppets provide, the visual thread. With a little effort and imagination, you can make your own glove puppet.

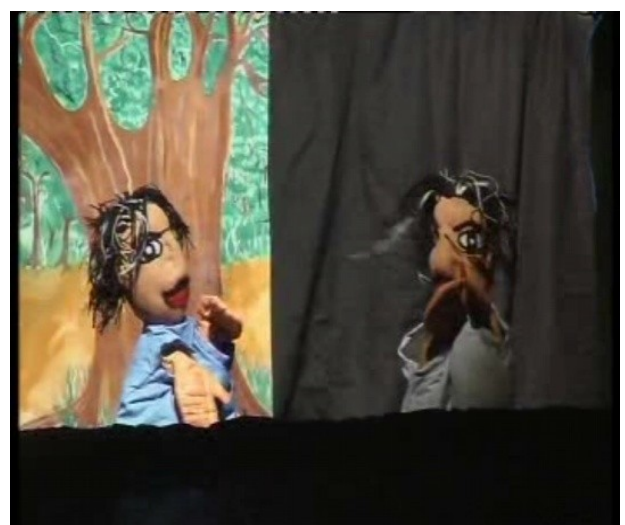

Figure 4: Glove Puppet show

Glove puppets are also known as sleeve puppets, hand puppets or palm puppets. The glove puppet in Orissa is called Kundahei Nach. The glove puppets of Kerala are more ornate, colourful and resemble the actors on the Kathakali stage in their make-up and costume. Their performance is known as Pava Koothu or Pawa Kathakali. The stories of this theatre are mainly based on Radha and Krishna and the Ramayana.

In Orissa, the play of glove puppets is called Kundhei Nach (kundhei means 'doll' and nach means 'dance'). Another glove puppet tradition is Gulabo-Sitabo, performed in and around Lucknow since the $17^{\text {th }}$ 
century. Gulabo and Sitabo are shown as two women characters who are married to the same man. While Gulabo is shown as an arrogant and domineering wife, Sitabo on the other hand, is portrayed as one who is docile and submissive. Earlier the heads were painted and crafted in wood, but for the last hundred years or so, papier mache is used. This art is fast declining owing to lack of patronage and the advent of popular mass media. Another glove puppet tradition thriving in the Medinipur district is Benir Putul Naach. The heads of the puppets are made out of terracotta and the hands and stumps are carved out of wood. The puppets have bells and cymbals attached to their wrists. This group of glove puppeteers is composed of itinerant performers who move from one place to another with their performances.

\subsection{Rod puppets :}

Rod puppets are an extension of glove puppets but often much larger. They are fixed to heavy bamboo sticks which are tied to the puppeteer's waist. These are three-dimensional moving figures that are manipulated with the help of rods. The traditional rod puppet form of West Bengal is known as Putual Nauch.

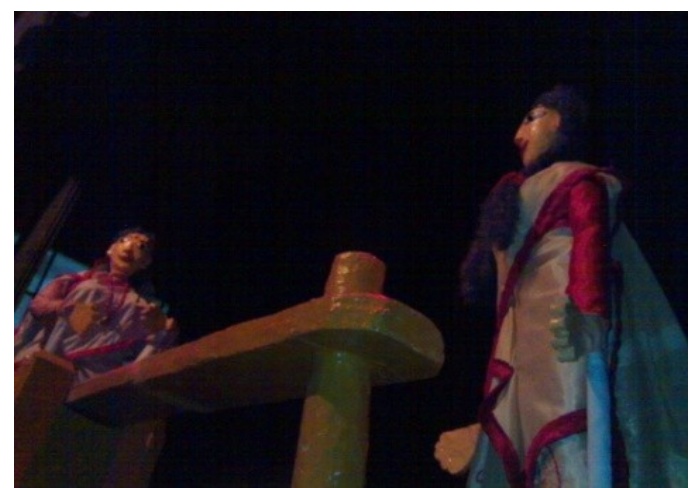

Figure 5: Rod Puppet show

Traditionally, rod puppetry prospered in the states of Orissa and Bengal. The rod puppets in Orissa are called Kathikundhei Nach (rod doll dance). The rod puppeteers from Orissa perform extensively from the Ramayana and also the popular narrative of Mahishasurmardini, the story of Durga slaying the demon Mahisha. The puppets are about 60 centimeters in height; their heads are carved out of wood and are painted. Bengal's tradition of rod puppet performance is known as Daanger Putul Nach. The themes of this performance are derived from the Ramayana, the Mahabharata, the Puranas and jatras. These rod puppets can be up to 1.25 meters in height and about 5 to 10 kilograms in weight. Their faces are painted in the pata style, with clay or a cloth layer upon it. The performances are characterized by high pitched singing and dialogue delivery accompanied by elaborate costuming, thereby pproximating closely in style the popular jatra performance. These puppeteers belong to the southern regions of West Bengal. The group normally consists of a lead singer accompanied by 18 other members.

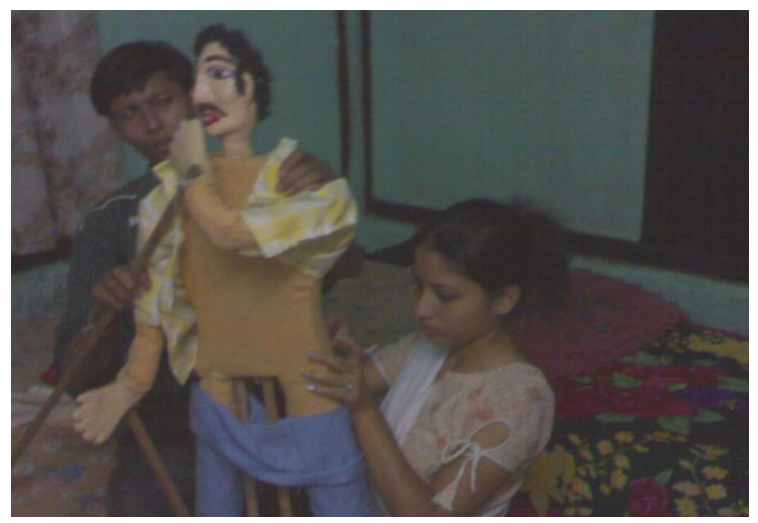

Figure 6: At the time of Puppet parts joining

\subsection{Shadow puppets :}

In this form, shadows of puppets are used in black and white or in colour. The flat figures, usually made of leather, are lightly pressed on a transparent screen with a strong source of light behind. The screen thus forms the barrier between the audience and the puppet, creating the projection of image. The impact on the audience, surrounded by darkness all around, is quite dramatic. The screen in India is a simple sheet stretched on 
an adjustable frame. Perhaps one of the oldest forms of puppetry, shadow puppets are found in the states of Andhra Pradesh, Karnataka, Kerala, Maharashtra, Orissa and Tamil Nadu. Ravan Chhaya from Orissa and Tholpavai Koothu from Kerala are the two prominent shadow puppet theatre traditions of India.

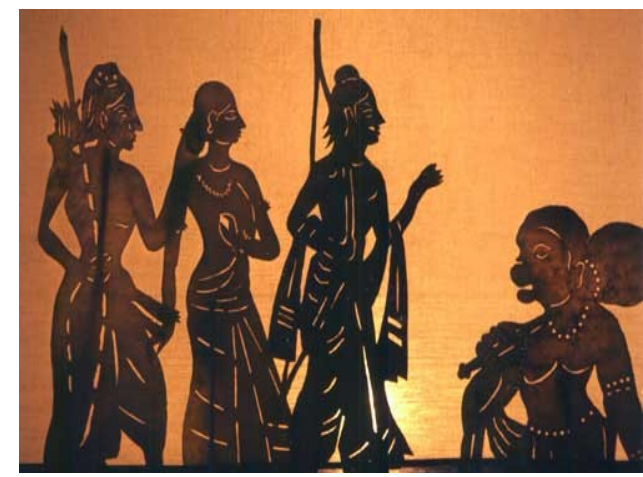

Figure 7: Shadow Puppet

The traditional performers of Ravan Chhaya are from the community of bhats who received the patronage of the local rajas of Pallahara in the shape of land grants. The puppets are made from the skins of deer, mountain goats and sheep and they are not painted so as to retain their natural colours. Sizes of the puppets vary from less than 20 centimeters to over 60 centimeters, with no joints. This tradition is named after Ravan as it is believed that Ram, a divine and illuminated being, does not cast a shadow. The story is taken from the Oriya version of the Ramayana called Vichitra On the other hand, Tholpavai Koothu is an ancient form of art dedicated to goddess Bhagavathi, worshipped by the Hindu community of Kerala as the Mother Goddess. The puppets are opaque, thus casting black and white shadow, mainly in sitting or standing profile. Episodes from the Tamil Ramayana $17^{\text {th }}$ by Kamban (12 century) and Sanskrit plays like Mahanatak are suitably adapted for these performances.

\subsection{Paper Puppet:}

Paper dolls are figures cut out of paper or thin card, with separate clothes, also made of paper, that are usually held onto the dolls by folding tabs. They may be a figure of a person, animal or inanimate object. Paper dolls have been inexpensive children's toys for almost two hundred years. Now Paper dolls have been used for advertising, appeared in magazines and newspapers, and covered a variety of subjects and time periods. They have become highly sought-after collectibles, especially as vintage paper dolls become rarer due to the limited lifespan of paper objects. Paper dolls are still being created today.

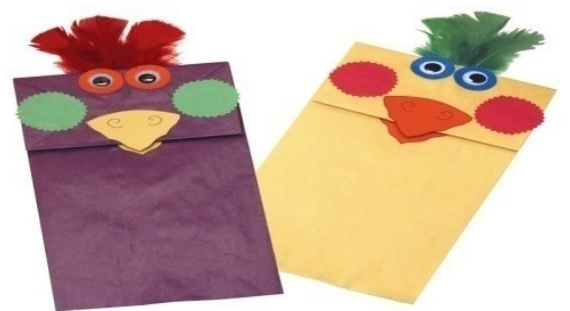

Figure 8: Paper Puppet

We make a Paper Puppet

1st we need a blank sheet of paper and a pen.

- Fold the paper in half long ways

- Fold it again.

- Fold it in half to make a crease in the middle.

- Now open it back up.

- Now fold each end towards the middle crease.

- Now fold it once more.

- Grab our pen and draw 2 eyes, nostrils, and a tongue.

- Slip our index \& middle finger in one hole, and our thumb in the other hole.

- we got our self a paper puppet! 


\subsection{Water Puppet:}

Water puppetry is a traditional art form native only to the Vietnamese. This particular craft is highly intricate, despite the simplicity of the imagery and storylines. Water puppetry is a tradition that dates back as far as the 11th century CE when it originated in the villages of the Red River Delta area of northern Vietnam. Today's Vietnamese water puppetry is a unique variation on the ancient Asian puppet tradition.

The puppets are made out of wood and then lacquered. The shows are performed in a waist-deep pool. A large rod supports the puppet under the water and is used by the puppeteers, who are normally hidden behind a screen, to control them. Thus the puppets appear to be moving over the water. When the rice fields would flood, the villagers would entertain each other using this form of puppet play.

Modern water puppetry is performed in a pool of water 4 meters square with the water surface being the stage. Performance today occurs on one of three venues - on traditional ponds in villages where a staging area has been set up, on portable tanks built for traveling performers, or in a specialized building where a pool stage has been constructed.

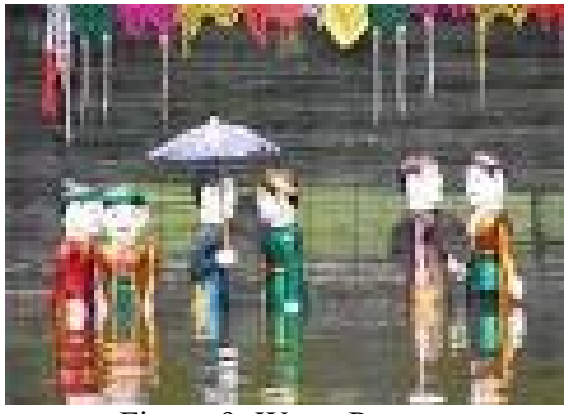

Figure 9: Water Puppet

Up to 8 puppeteers stand behind a split-bamboo screen, decorated to resemble a temple facade, and control the puppets using long bamboo rods and string mechanism hidden beneath the water surface. The puppets are carved out of wood and often weigh up to $15 \mathrm{~kg}$.

A traditional Vietnamese orchestra provides background music accompaniment. The instrumentation includes vocals, drums, wooden bells, cymbals, horns, gongs, and bamboo flutes. The bamboo flute's clear, simple notes may accompany royalty while the drums and cymbals may loudly announce a fire-breathing dragon's entrance.

Singers of a form of opera originating in north Vietnam sing songs which tell the story being acted out by the puppets. The musicians and the puppets interact during performance; the musicians may yell a word of warning to a puppet in danger or a word of encouragement to a puppet in need. The puppets enter from either side of the stage, or emerge from the murky depths of the water. Spotlights and colorful flags adorn the stage and create a festive atmosphere.

\section{Puppet Making}

We make our puppets the same way we design our sets - in a kit form. We like to maintain flexibility throughout rehearsals - often a show is devised from scratch - often we do shows that are entirely improvised on the night. Our larger scale productions usually involve a great deal of design. A balance always needs to be struck between maintaining this flexibility and making early decisions to allow time for the different design elements to be made. We have found that by using kits we are able to strike this balance in a satisfying way. Often this means the design has to come first. SHOCKHEADED PETER was an example of this. We decided to design a fully contained eccentric theatre in which to stage our show. We wanted it to have its own flying system and a myriad of doors and various hatches. In addition to the old elements, we decided on new elements - a set of cut out gravestones for example. We made extra puppet bits, but not whole puppets - various heads and torsos, arms and legs. All of this was made before we even knew the story.

It is good when designing like this to make some definite decisions that don't yet have a reason to them. For example, decide that there will be a number of trap doors or a large piece of silk without yet knowing how you are going to use them in the show. This involves trusting that the creative process will reveal to you or will tell you why you made these intuitive decisions.

In many of our productions the puppets are made from scratch on the night, in front of the audience. This is something that we have discovered the audience really enjoy. In 70 HILL LANE the sellotape that was used by the performers to define the walls and fabric of houses, staircases, corridors and furniture was cut down and drawn together to create an ethereal figure that strode across the stage before transforming into a silvery globe. 


\section{Future Scope \& Related Work}

We hope that the fact that puppetry is part of a show will no longer become an issue - that it is considered in the same way as text, design or movement as part of our available theatre vocabulary. When an aspect of theatre has been marginalized and then becomes more adopted by the mainstream there is excitement that people begin to see its value but there is also simultaneously a sense of loss become because puppetry perhaps loses some of its sense of being special. It is no longer just ours but belongs to everybody.

We worry that something dear to us has just become a fashion. Perhaps the way to make sure puppetry is used well is to remember why we first used puppets and what things were trying to be said by these strange creatures and ensure that when we use them we are truly speaking from that space. If we are just using them because they are the next "in" thing then we should put them aside for a while and wait till they want to join in again.

\section{Conclusion}

The project indicates that puppets can provide a useful mechanism to enhance children's engagement and to promote talk involving reasoning in primary science lessons. There is evidence that when teachers use the puppets children talk more readily about scientific problems and higher-order thinking is promoted. They can be particularly significant in engaging reluctant speakers, such as shy children, and promoting greater involvement in scientific discussion with these children. The puppets appear to be effective in providing an interactive narrative which sets a context for learning and provides a purpose for children's talk and follow-up activity. In Puppet dance refreshment of human life. Puppet dance most important in educational courses. Many universities introduced of puppetry chapter in higher education course (i.e Mass Com, Folklore, Literature Subject etc). Film Maker introduced in his film. Now Puppet maker scientifically developed of puppet making. All puppet dances mostly attractive of new generation in world. We prepare different modern story introduce in puppet show time.

Today, while puppetry has made its way into the cities, traditional puppetry is dying a slow death. Modern puppetry on the other hand, is gaining momentum, albeit slowly, and is often used as a tool for imparting social messages. Puppeteers now tell stories on everything from medieval kings, 'Phulan-Devi, 'Aladin', 'Tejimala', 'Witch-Craft' to AIDS because to survive in this digital world, revolution has become a necessary component for this centuries old craft.

[1]. Learning With Puppet, amrita kather,

\section{References}

[2]. Qualitative Evaluation of the African Research and Educational Puppetry Programme (AREPP), C.Evian B.Oskowitz Z.Hlatshwayo.

[3]. The Potential of Puppetry A Review of the Sector in Scotland.

[4]. "Putlanasor itibritya", Binita Devi. 